\title{
Privatising Public Prisons: Penality, Law and Practice
}

\author{
Alison Liebling \\ University of Cambridge, United Kingdom \\ Amy Ludlow \\ University of Cambridge, United Kingdom
}

\begin{abstract}
In October 2011, HM Prison Birmingham was transferred from public to private management, under G4S. This was the first time that an existing operational public prison was privatised in the UK. The move marked the third and most far reaching phase of prison privatisation policy, and was intended both to increase quality of life for prisoners, from a low baseline, and to reduce costs. Prior to 2011, private prisons had all been new-builds. Private contractors had thus far avoided the additional challenges of inheriting a pre-existing workforce and operating in old, often unsuitable, buildings. This article reports on a longitudinal evaluation of the complex process of the transition, and some outcomes for both staff and prisoners. As an experiment in the reorganisation of work and life in a 'traditional' public sector prison, the exercise was unprecedented, has set the agenda for future transformations. The example illustrates the intense, distinctive and rapidly changing nature of penality as it makes itself felt in the lived prison experience, and raises important questions about the changing use of State power.
\end{abstract}

KEY WORDS: PRIVATISATION, PRISONS, STATE POWER, MORAL QUALITY, CULTURE, REFORM 
David Garland suggests that in order to explain penality, scholars should 'attend more closely to the structure and organisation of the penal state' (2010, p. 476) and that we should focus more systematically on governmental and legal processes, particularly in explaining penal change. We agree wholeheartedly. Noel Whitty has described prison scholars as 'law avoidant' (Murphy \& Whitty, 2016). Other criminologists have made similar observations (A Bottoms, personal communication) and have also called for more attention to be paid to the complex relationship between state power, rules and behaviour (for example, Dixon, 1997 and Baldwin \& Kinsey, 1985 in policing). Changing legal and other structural frameworks are impacting deeply and swiftly on prison leadership, life, culture and quality in England and Wales (more deeply and swiftly then elsewhere, we propose ${ }^{1}$ ) with insufficient attention being paid to their purposes or effects. Privatisation and competition are the most obvious areas where the law, or formal 'deployment of the power to punish' has changed (Garland, 2010, p. 21), but other associated changes to the terms and conditions of imprisonment (e.g., benchmarking/cost reductions, changing performance measurement requirements, and the building of larger prisons) are also making a significant impact. These are 'sociologically significant activities' (Power, 1997) with serious implications for models of penal order, for the ways in which power works, staff operate, and prisoners live, in prison, as well as for outcomes. This case study suggests that we should add to Garland's ambitious research agenda close and empirical-longitudinal scrutiny of single sites as they adapt, imperfectly and with much strain, to the changing penal field. The intense, distinctive and rapidly changing nature of penality shows up, often dramatically, in the prison experience. Our analyses should be focused both on day-to-day accounts of 'how punishment feels' and state action. The shape and tone of prison life is being energetically crafted by state actors, not always competently (Le Vay, 2016), with some intended and many unintended effects on those who are subjected to it.

\section{The changing penal state: the case for privatising public prisons}

In a Report into the state and use of prisons, the House of Commons Home Affairs Committee (HAC) identified a series of well-known problems facing public sector prisons (HAC, 1987a): aged buildings, overcrowding, high costs and hostile industrial relations. This Report was swiftly followed by a second, highly influential HAC Report on the Contract Provision of Prisons, in which the Committee called for 'urgent new ways' of tackling these difficulties and recommended, 'as an experiment', the use of the private sector to construct and manage new prisons (HAC, 1987b).

Four years later, as the first private prison was due to open, Martin Narey, then Chief Executive of the Prison Service, linked the failings of public sector prisons to morality. At a Prison Governors' conference in 2001, he said:

I am not prepared to continue to apologise for failing prison after failing prison. I've had enough of trying to explain the very immorality of our treatment of some prisoners [...]. We have to decide, as a Service, whether this litany of failure and moral neglect continues indefinitely [...]. It's a matter of caring, a matter of determination, and, I accept, not a little courage in taking on a culture in all too many places which we have allowed to decay [...]. The prize is [...] a Prison Service of which we need no longer be ashamed (Narey, 2001, p. 3).

The existence of 'failing prisons' was a problem of courage and care as well as management competence. The private sector was invited to lead urgent reform, and public sector Governors were challenged to follow suit. Complex arguments about the ethical risks of punishing for profit, as well as arguments over variations in, and measurement of, performance in the public sector, were side-stepped as the moral case for cultural and management improvements to prison operations took hold in a

\footnotetext{
${ }^{1}$ Although many jurisdictions, including Australian States, are following suit.
} 
political context of deep commitment to a 'New Public Management' agenda (Hood, 1991; Ascher, 1987; Harding, 2001).

Some of the problems holding back change in the public sector were due to the resistance of the Prison Officer's Association (POA), the trade union representing most prison staff. Whilst prison culture and quality varied significantly, many public sector prisons - particularly those in large inner cities - were characterised by negative and reluctant staff cultures, neglectful regimes and practices, and high costs. The reasons for these failings were complex, and a programme of management reform including better performance measurement had begun. Privatisation was advocated for ideological reasons as well as a source of improvement, innovation and competition: a spur to greater efficiency and better performance across the board.

The privatisation 'experiment' started with management-only contracts, and checks on the devolution and control of delegated powers. Under s.85 of the Criminal Justice Act 1991, a private prison Director was not empowered to conduct any disciplinary hearings against prisoners and generally could not order the removal of a prisoner from association with other prisoners, order the temporary confinement of a prisoner in a special cell or order the application to a prisoner of any special control or restraint. These functions were instead fulfilled by a Controller; a state employed contract monitor and adjudicator (see further James, Bottomley, Liebling \& Clare, 1997). However, the 'experiment' quickly developed to include longer contracts incorporating the financing, design, and management of establishments, and many of the original constraints on the powers of Directors were loosened (see Ludlow, 2012).

In the years that followed, 11 private prisons were opened, and a series of competitions for existing prisons were held. The public sector retained one contested prison in this first round (HMP Manchester), and won one back from the private sector (HMP Buckley Hall). At some establishments (such as the Isle of Sheppey prison cluster in 2005), internal performance improvement processes were used rather than competitive tendering. This provoked criticism from the Confederation of British Industry (CBI) on the grounds that expectations of new business had been raised. ${ }^{2}$ However, no bids came in at an affordable price for the first 'traditional/ancient' local prison placed on the market in 2001 (HMP Brixton). The constraints on potential bidders for HMP Brixton included employment law requiring the retention of staff on existing pay and conditions, ${ }^{3}$ and the limitations inherent in the prison's dilapidated and unsuitable buildings. The prison was described in various reports as 'brutal, squalid and chaotic', and even its Governor described it as 'inhuman and degrading' and was 'worse' in 2001 than it was 'in the $70 s^{\prime}{ }^{4}$ Sickness absence among staff was high. As in other public sector prisons, improvements were overdue, but the competition was abandoned when the private sector could not be persuaded to bid for it. The prison has remained in the public sector since, with few signs of improvement to its basic conditions or culture to date, despite an improbable change of function to Category C/D resettlement prison in 2013 (e.g., HMCIP 2011; Crewe, Liebling \& Hulley, 2014).

Over the years to follow, the Government strengthened its formal commitment to prison competition. The National Offender Management Service (NOMS) was created, as an amalgamation of the former Prison and Probation Services. One of the aims of this restructuring was to improve the delivery of competition policies (Carter, 2003, 2007; Home Office, 2004). The powers of private prison Directors and the role of public sector Controllers were revised in favour of greater private sector responsibility by the Offender Management Act 2007. This signalled a new level of trust in private sector operators and sent a positive message to the market about the future role of private service delivery (Ludlow, 2012).

\footnotetext{
${ }^{2}$ http://www.ft.com/cms/s/0/2bc2a9ee-e905-11d9-87ea-00000e2511c8.html\#axzz2HP4EqbZE.

3 The Transfer of Undertakings (Protection of Employment) Regulations 2006.

${ }^{4}$ http://www.theguardian.com/society/2001/jan/31/prisonsandprobation.
} 
During this period, evidence on the quality and cost of new privately managed prisons, and their effects on performance in the Service overall, was sparse, but somewhat promising in parts (e.g. NAO, 2003; HMCIP, 2002; Liebling with Arnold 2004; Shefer \& Liebling, 2008) particularly in areas such as staff culture, and responsiveness to management requirements. The evidence was less positive in areas like safety and security (James et al., 1997; Liebling with Arnold, 2004). These studies precipitated an animated debate about how to measure relative cost and quality.

\section{Conceptualising and measuring prison quality}

In 2006, Liebling and Crewe secured a large Economic and Social Research Council (ESRC) research grant to conduct a project, Values, Practices and Outcomes in Public and Private Corrections. The study was shaped by previous research by both investigators on prison life and quality. Fieldwork comprised extensive survey data collection in two matched public and two private prisons, alongside interviews with over ninety senior managers in both sectors about their professional values, backgrounds and motivations. ${ }^{5}$ The prison quality survey developed for these purposes had its origins in earlier studies of what mattered to prisoners in measuring prison quality, and had been revised over the course of several specific investigations (for example, of prison suicide prevention; see Liebling et al., 2005). The survey has been adopted by NOMS since 2004 for routine use in all prisons, and in that capacity is known as 'Measuring the Quality of Prison Life' (MQPL).

The findings of Liebling and Crewe's ESRC study can be summarised as follows:

- There were significant differences between staff cultures in the two sectors. Even in struggling private sector establishments, staff reported feeling relatively safe and expressed high levels of trust in their managers. Relative to the public sector, uniformed staff were more positive about their work and their employers, despite less preferable salaries and conditions in the early stages.

- Staff in public sector prisons were more likely to adhere to a 'traditional' or 'heavy' culture, which could be related to some negative consequences for prisoners, including feelings of unfairness and lack of care. On the other hand, experience was also related to a more positive 'traditional-professional' orientation amongst many public sector prison staff, which prisoners welcomed. There were indications that a traditional (negative) culture was developing among uniformed staff in the more established and once higher-performing private sector establishments, as well as evidence of some benefits as more experience accrued.

- While results gleaned from earlier studies suggested that the private sector might outperform the public sector in areas such as 'decency', 'humanity' and 'trust', the findings from the main four-prison comparison revealed higher scores in the public sector prisons than in the private sector prisons on a large number of dimensions, including 'harmony' (relational) as well as 'security' dimensions, such as respect, staff-prisoner relationships; and staff use of authority, respectively. However, two of the private sector prisons added to the study obtained generally higher prisoner quality of life scores than all four prisons in the main study. These prisons were in many respects, outstanding.

- Private sector prison staff struggled more than their public sector counterparts with the use of authority. Some private sector prison staff had a tendency to under-use power or use it in arbitrary ways. There was a tendency for under-policing, even in private sector establishments that were otherwise high-performing. In the two public sector prisons in the study, prisoners were more likely to describe officer power being used appropriately (that is, for order and

\footnotetext{
${ }^{5}$ Dr Susie Hulley and Ms Clare McLean also worked as part of the research team.
} 
safety, as well as getting things done for prisoners), although there were indications that power was sometimes over-used.

- A weakness of the private sector was staff knowledge and competence, particularly in longerterm training prisons, where prisoners needed considerable assistance with sentence plans. Prisoners in private sector establishments described staff as 'nice people' but felt that they lacked expertise on issues that mattered to them, particularly in helping them to navigate through increasingly complex sentence conditions. Staff turnover was high.

- Prisoners in the private sector prisons reported feeling more frustrated and stressed by their 'lighter' but less organised prison experiences. Those in the public sector reported stronger feelings of being punished by their prison experience.

These findings were conceptualised using the terms 'heavy' and 'light': public sector prisons tended to be 'heavier' - infused with authority, whereas private sector prisons tended to be 'light' and unsafe. Staff were sometimes 'absent', or insufficiently active in managing trouble (Crewe, Liebling \& Hulley, 2011, 2014). Better prisons combined the strengths and minimised the weaknesses of both sectors. In these better prisons, prisoners described feeling more able to work on their offending behaviour and personal development.

There are grounds, then, for evaluating both public and private sector prisons closely, and for learning lessons about variations in approaches to staff recruitment, deployment and management following competition, and their effects. The privatisation of existing prisons, the new lean model being established in public sector prisons as they fight back, and the extensive contracting out of 'services' to prisoners, together mark a dramatically new phase in the prison management 'experiment'. An intense, distinctive and rapidly changing form of penality is taking shape, and is having major effects on the experience of staff and prisoners, but to date this model has little 'theory' or evidence underpinning it. The authors of this article were both engaged, in different capacities, in research projects at the first existing and operational prison in England and Wales to be privatised (HMP Birmingham) during the prison's competition and transition to G4S, as well as thereafter, ${ }^{6}$ and have been pursuing relevant changes in other prisons, with others, since. We draw on these projects to describe the transition process in particular, reflect on its significance, and outline the findings on the effects to date.

\section{A case study: the first public to private sector prison}

\section{(i) The stakes}

In April 2009, when the competition for HMP Birmingham was announced, it was clear that this would be a 'game changing' competition. The announcement of further competition was not itself surprising. The Ministry of Justice had made a strong policy commitment to competition in its 2009 Capacity and Competition Policy. What made the announcement so noteworthy, then, was its potential to result in the first transfer of an operational public sector prison to the private sector in the UK. This had enormous workforce implications. As described above, prior to 2011, private UK prisons had all been new-builds and none of the competitions had resulted in a public prison being transferred to a private company. ${ }^{7}$

\footnotetext{
${ }^{6}$ For example, the direct invitation to lead a team evaluating its quality as perceived by prisoners and staff shortly after transition to G4S, and then one and two years later (Liebling et al., 2012, 2013, 2015); the supervision of an MPhil/PhD student exploring the use of User Voice at HMP Birmingham (amongst others) (Schmidt, 2013); and a PhD exploring the workforce implications of privatisation, using Birmingham as its key case study (Ludlow, 2015).

${ }^{7}$ There is precedent for such a transfer in Australia. The Parklea Correctional Complex in Western Sydney was taken into private management by GEO Group Australia on 31 October 2009. The terms and methods of
} 
Private contractors had thus far avoided the additional challenges of inheriting a pre-existing workforce and operating in old, often unsuitable, buildings. If a private bidder was successful in the 2009 competition, it would need to deliver savings and service improvement in unfamiliar territory. This would also signal an end to public sector confidence that they could resist new lean models of prison staff deployment.

HMP Birmingham was put out to tender because of poor performance. It was one of the prisons named by Martin Narey in his 'failing prisons' speech. The prison shared many of the characteristics of HMP Brixton, the subject of the first abortive attempt at market testing an existing prison, described above. Birmingham is a large Victorian local that has a long history of reported brutality, 'idleness and neglect' (HMCIP, 2000), and of Governors leaving under stress following attempts to improve it. Sir David Ramsbotham's Inspection Report of November 2000 opened with, 'Virtually everything about this long, detailed and appalling report is depressing and disturbing.' The prison had a strong local Prison Officers' Association (POA) branch and a reputation for having a 'traditional' (negative, resistant) staff culture, or a staff culture that is 'trapped in the past' (HMCIP, 2000). A pre-transfer MQPL survey was conducted in May 2009. 83.8\% of prisoners at Birmingham scored their overall quality of prison life negatively.

Although HMP Birmingham was in obvious need of improvement, there was a sense of disbelief among Birmingham's staff about the competition. Many felt that Birmingham was too large, too industrially powerful and 'too dangerous a proposition for the Government to take on'. If Birmingham prison was transferred into private sector management, then the rules of the game would be changed irrevocably, leaving all public sector prisons vulnerable to future competition. As one Senior Officer put in, 'In the back of all our minds, everyone thinks it won't happen to Birmingham, it can't, they wouldn't dare. ${ }^{8}$

There were, however, several important ways in which HMP Birmingham was in a different position to Brixton. First, as the CBI's criticism of the decision to use internal performance improvement on the Isle of Sheppey suggests, there was a risk that private sector interest would wane. If competition policy was to have long-term credibility, the threat to the public sector, and promise to the private sector, of takeover at some stage needed to be made real. The Government needed to demonstrate to the private sector that the UK prison market was worth its investment. Secondly, in the wake of the financial crisis, there were more pressing fiscal imperatives to achieve immediate financial savings. In this context, privatisation was seen as an especially attractive solution since it enables costs, and therefore risks, to be fixed and transferred rapidly. Thirdly, the political landscape and policy context had changed since the failed attempt to compete Brixton. Whilst the Birmingham competition was launched under a Labour Government it was completed under the Conservative/Liberal Democrat Coalition. It would have been surprising for the competition to have been aborted by the Coalition, given the strong alignment between privatisation and Conservative politics which have predominated within the Coalition. Furthermore, since Brixton, a more powerful prison procurement body had been created within NOMS. These three factors made it more likely that the Birmingham competition would be a 'game changer'. The Government could not afford another failed Brixton competition.

\section{(ii) The Birmingham 'revolution'}

On 31 March 2011, after a two year procurement process, the outcome of the Birmingham competition was announced. As the Justice Secretary rose to address the House of Commons, the Governor read out the news that G4S had been awarded the contract to manage HMP Birmingham. Thereafter, the prison

\footnotetext{
transition were different, not least because there is no obligation to transfer existing staff to the new operator under Australian employment law.

${ }^{8}$ These quotations are taken from a total of 60 semi-structured interviews carried out with Birmingham staff during the competition and transfer to G4S. See Ludlow, 2015. Later quotations are from ongoing research being conducted by both authors.
} 
entered into a transition phase that ran until 1 October 2011, when management of the prison was formally transferred to G4S. 1 October 2011 was therefore an historic day. As a NOMS Senior Manager described, 'The Birmingham announcement is one of the most momentous decisions in the Prison Service since the nationalisation of local prisons in 1876'. But in most visible respects, 1 October 2011 was an anti-climax. There was some rebranding around the prison and staff wore a different uniform, a significant indicator to them of their new and, at the time, unwelcome status. But everything else seemed just the same as it had been.

A team from the Institute of Criminology in Cambridge was invited by HMP Birmingham's new Director to conduct a detailed survey and observational study of staff and prisoners' perceptions of their quality of life shortly after transition to G4S in December 2011, and again, one and two years into the contract, in December 2012 and 2013. This invitation reflected the new Director's genuine commitment to delivering improvement, but it also reflected his awareness that improving Birmingham was going to be a difficult task. We present the findings of this work below and consider their implications, with other major transitions in mind, below. Before turning to outcomes though, we reflect upon the process of competition and the ways in which such processes shaped prison life. We note an interesting divergence between perceptions of success amongst establishment staff and NOMS management in the immediate aftermath of the contract award announcement.

Researcher:

NOMS Senior Manager:

Birmingham Senior Officer:
'Do you think this competition has been a success?'

'Yes it has. It's been a clean process. Obviously the bidders that didn't win weren't pleased but everyone agrees that it was a fair process. We managed to avoid any leaks. Nobody knew until the Minister stood up in the House of Commons. That was a big achievement. We've proved to the private sector that the prisons market is worth investing in.'

'Success? I dunno what they were trying to achieve. Four staff were sent off duty during the last ten days because they were crying and shaking uncontrollably. We sent another two off in the last week for alcohol related issues. You see everyone in the car park before work psyching themselves up, in tears, doing their best to come into work. If that's what they wanted then I guess they've got it yeah. We're broken. I don't know anymore.'

The Senior Manager thought that the competition had been a success because it had been 'a clean process'. The decision had not been leaked before the Minister's official announcement and the commercial integrity and 'competitive neutrality' of the competition process had been honoured. NOMS had demonstrated that its staff could make (controversial) procurement decisions and retain control until the time of official release of that information. This was taken to indicate that power now resided with NOMS rather than the POA and underscored the procurement team's integrity and competence, all of which would give the private sector confidence to invest in future prison competitions.

By contrast, the dominant view amongst Birmingham staff at all levels was that the procurement process had been a betrayal. As one Manager said, 'I'm used to the Winson Green [HMP Birmingham] way of having a knife stuck in your back but now they're sticking it between your eyes.' The process had been emotionally and psychologically destabilising for staff. They described the process as a 'sword' above their heads, over which they had no control. Prison Officers reported that they had 'lost their corporate identity' and that 'money rather than people now ruled the roost'. This manifested itself in decreasing morale and trust between staff, and increasing apathy towards their work. 
This divergence between perceptions of success - between a manager who focused narrowly on a successful process outcome and a Birmingham officer who described deep trauma - tells us that different stakeholders have different experiences, as well as widely differing criteria, for evaluating 'success'. The more negative experiences of competition by staff on the ground played a constraining role in improving Birmingham's future.

This divergence also illustrates a more general theme that came to light in this case study, namely a conflict between the competition process requirements and reform objectives on the one hand, and fairness, or care, for employees who were affected on the other. Despite the existence of more than 30 documents specifying principles, articulating statements of practice and offering guidance on the inclusion of workforce matters in procurement, this guidance did not translate into defensible staff experiences of competition at Birmingham. A concern to ensure that the procurement process was commercially rigorous was allowed to marginalise day-to-day and post-transfer workforce issues. The cultural improvement agenda, for which the competitive process was introduced, appeared neglected as a result of the focus upon procurement process. Whilst staff at Birmingham were arguably 'culpable' in culturally resisting reform, as well as bringing about or colluding with an unacceptable culture in the first place (which they typically cannot diagnose or recognise whilst working in it), many were willing to participate in improvement, and as in any prison, some had been doing outstanding work all along. The problem of how to challenge a workforce, overcome resistance, and then secure willing cooperation with a future management agenda had never been satisfactorily considered. No 'model' of improved 'delivery' (what we might refer to as a legitimate form of order) had been articulated, to which a newly formed workforce could work.

Competition became an end in itself rather than a process by which to secure better practices and value for money. This echoes Labour's criticisms of compulsory competitive tendering (CCT): 'All too often the process of competition has become an end in itself, distracting attention from the services that are actually provided to local people. In short, CCT has provided a poor deal for employees, employers and local people. CCT will therefore be abolished.' (DETR, 1998). The way in which the law was understood and mobilised played a significant role in the creation of this state of affairs. Contracting in this way (that is, competing whole establishments, or at least competing establishments in such a protracted manner, specifying standard outputs but leaving the real problem areas of staff attitudes and practices, weaknesses in management, or unclear penology, unresolved) may not be the most suitable or effective way to improve services. Where the original institutional problems are primarily cultural and penological, the solutions need to go beyond new contractual arrangements.

\section{(iii) How competition became an end in itself}

Unlike private parties, when the Government chooses to put its services out to tender, it must comply with an additional set of public procurement rules that have their roots in European Union (EU) law. The Government's fundamental obligations are to treat economic operators equally and to act in a transparent manner. This implies the imposition of a variety of compulsory procedural duties (such as a mandatory standstill period between the notification of the contract award decision and the entering into any contract of at least ten days) and, to some extent, constrains an authority's choice and conduct of competitive procurement processes. In the case of prisons, a more limited set of rules applies, on grounds of an anachronistic (and now removed) distinction between so-called 'Part $A$ ' and 'Part B' services. Part B services, of which imprisonment is an example, are considered to be of greater local interest and thus of less cross-border (and therefore European) interest. Constraint authorities therefore enjoy greater discretion in their choice and conduct of competitive processes in these areas, albeit that there is still an overriding requirement to ensure equal treatment and transparency. 
With this background in mind, it is noteworthy that NOMS considered the procurement rules to apply in full to the Birmingham competition and thereby denied itself some procedural latitude that it could have otherwise enjoyed. Such a defensive decision can be explained by both the complexity of the procurement rules and the high risks and penalties of non-compliance. The 2012 West Coast rail fiasco, in which a contract award decision was overturned following a challenge to the integrity of the bid evaluation procedure by one of the bidders, provides a good illustration of the financial and reputational risks of procurement errors. ${ }^{9}$ Competitive processes that run smoothly are already very expensive. The cost of running the Birmingham competition is reported to have been $f 5.84 \mathrm{~m}$ (Prison Reform Trust, 2011, p.72) and, although private bidders must cover their own bidding costs, participation expenses inevitably impact upon future bid pricing. Retendering adds significant further cost and sends a damaging signal to the market about the contracting authority's competence. There are therefore good reasons for contracting authorities to tread carefully when running a competition.

However, regulatory complexity can cause problems. The complexity of the procurement rules, and the high risks of non-compliance, contributed to the domination of process concerns over questions about substance (improved prison quality, culture and outcomes). Procurement was seen as a highly specialised function, to which few NOMS' staff could make a contribution and which, consequently, was isolated organisationally. 'Ethical walls' were erected within NOMS to prevent the perception among private sector bidders of the public sector having an unfair tendering advantage. However, at times, the 'walls' had prejudicial operational impacts, partly because their underlying purpose had not been properly explained to NOMS staff. Expertise was not always sitting on the 'right' side of an ethical wall, where it was most needed.

There was a gap between the political vision of competition, as a source of rapid, inherent improvement, and the realities of managing such a process. Constrained by the political mandate for competition, NOMS did not have the power, time or foresight to reflect adequately upon what a competition of this nature would mean for it as an organisation financially, culturally or operationally. It did not develop a clear vision of what it sought to achieve by putting HMP Birmingham out to tender and did not relate that vision to the process of competition: 'What the Board seemed not to realise is that the idea and reality of competition are actually very different. There was no consideration about the appropriate balancing of resource. We haven't thought about what competition means for us as an institution. There is lots of responsibility sitting with not many people who are not quite sure what competition means or how to deliver it. It is all a bit amateurish' (NOMS Manager).

There was little appreciation of the impact that the choice of a particular competitive procedure can have upon the dynamics of the process and therefore the outcomes that competition produces. Competition was mostly understood as a generic (rather than tailor-made and strategic) process. Nuances between the different types of competition, such as the varying levels of discretion retained by the contracting authority towards the end of the process or levels of necessary advance preparation, were generally poorly understood. NOMS did not articulate any vision of improvement upon which the Procurement Directorate could draw in constructing the competition dialogue sessions and drafting the final contract. Discussions thus centred upon delivering existing policies and standards rather than securing improvements. This is reflected in the final contract which is, perhaps inevitably, an operational or technical, rather than vision or direction-setting, document (see more generally, Le Vay, 2016).

Failing to think through the purposes of competition had a number of damaging consequences in the Birmingham competition. First, little thought was given to identifying Birmingham's enduring problems, or considering how competition (and the particular form that was used) would address those problems. Rather than identifying Birmingham's specific problems (poor management, a negative, resistant staff culture, an unclear penological purpose, and poor material conditions) and taking targeted action to

${ }^{9}$ http://www.guardian.co.uk/public-leaders-network/2012/oct/03/west-coast-rail-fiasco-procurement. 
address them individually, the whole prison was put out to tender. This may be more straightforward because it transfers all risk to a new contractor. More targeted solutions (such as bringing in specific external expertise) require greater creativity, long-term effort and on-going negotiation of risk and cost allocation. An organisation must also be able to identify, with help if needed, its own strengths and weaknesses. Whole-sale contracting out is by no means risk free. In the Birmingham competition, considerable time and cost were required to ensure that basic minimum standards were replicated by bidders, at the expense of discussions about how the prison's problems might be overcome.

Secondly, to the limited extent that workforce transformation was considered during the Birmingham procurement process, the law provided only a rather blunt tool for addressing such issues as part of a competitive process. This was partly a result of the public procurement rules, and partly a result of the inherent difficulties of expressing qualitatively sophisticated visions of 'right staff-prisoner relationships' or 'progressive management cultures' as contract terms.

The procurement rules frustrate efforts to bring about workforce transformation because they exert significant pressure upon contracting authorities to specify their service requirements in output terms. This is a manifestation of the non-discrimination rationale that underpins the rules: so long as a contracting authority receives the final good or service that it needs, bidders should have maximum discretion about how that good or service is delivered, so that tenderers from a wide variety of national contexts can compete. Improvements in output measures for prisoners (such as percentage of prisoners attending education or work) may be an indication of workforce improvements, but they paint only a partial picture. If workforce matters are not adequately included in the contract, the contracting authority is reliant upon the contractor's discretion in making workforce changes. Furthermore, since contracts are key to holding contractors to account, if workforce matters are unspecified, it is difficult for the contracting authority to police the contractor's performance.

The procurement rules can also make it difficult for contracting authorities to mandate minimum standards exceeding statutory minima in respect of workforce related processes. A contracting authority cannot demand that a contractor pays all staff a living wage, beyond the statutory minimum. This is because the European Commission takes the view that such clauses are not 'connected with the subject matter of the contract'. They do not alter the function or performance of the service that is provided: there are no functional differences between tables manufactured by labour paid a living wage or labour paid the statutory minimum wage.

Notwithstanding literature demonstrating that a fairly treated workforce makes good business sense and increases growth (e.g., Deakin \& Sarkar, 2008), the European Commission's view is that labour standards are a product of economic development but do not of themselves contribute to economic development. This view runs counter to British Government statements about the strong correlation between high quality employment practices and high quality services (see, for example, OGC, 2006, p.3; ODPM, 2003, p.37). There is strong evidence about the centrality of staff-prisoner relationships and the quality of management teams to prison quality and performance (Crewe et al., 2011; Liebling, 2011). There is also evidence that employment rights, practices and processes play an important role in shaping occupational cultures and identities (e.g. Sachdev, 2001). If staff feel ignored, devalued, demotivated and unfairly treated or rewarded, that is likely to affect their attitudes and performance.

Although the public sector prison employment model has weaknesses (such as unduly cumbersome performance management processes), it also has strengths, which a contracting authority might wish to retain, such as loyalty, commitment, workforce stability, experience and a sense of vocation or public service ethos. The public procurement rules make it difficult for a contracting authority to adopt a position on workforce matters during competitive processes. This makes it less likely that the strengths of the public sector will be retained. 
The third and, at the time of the Birmingham competition, most visibly damaging, consequence of competition 'becoming an end in itself', was the demoralising and disempowering manner in which the process was experienced by Birmingham staff. Inadequate preparation for the process resulted in multiple delays. A process that was intended to be concluded within less than a year took over two years. Such a lengthy and costly process risks unhealthy market dominance by large providers as small and medium enterprises are squeezed out, displacing the potential innovation and creativity they might bring, and replacing one (public) monopoly with another (private) monopoly. The protracted process was psychologically burdensome for staff. Distrust, anger, and disillusionment bred, as did feelings of professional devaluation and apathy. Staff suspected a 'stitch up', as the competition process stalled to take into account new (mostly disadvantageous) staffing policy developments, such as a review of pension protection for transferred public sector staff.

The damage that arose from the length of the process was compounded by NOMS' neglect of its ongoing responsibilities as an employer. Nobody spoke to staff in a language that they could understand. The POA was torn between a position of principled non-engagement with competition because of its objection to the policy and the realities of what their membership were experiencing: 'We get some information about the bid and stuff from the POA. But it's not in normal language, you can't understand it. It's in union speak' (Birmingham Prison Officer). This information void was unwittingly (and inappropriately) filled by the public sector bid team, who provided staff with general information about the process and its progress. When this team was disbanded, following a change to the competition process, no alternative arrangements for staff engagement were put in place.

This lack of information and support for staff had far-reaching effects, some of which occurred beyond Birmingham, in reshaping the texture and values of public sector prison employment relationships. As argued above, there may be some benefit to remodelling this relationship (for example, in making it more 'contractual') and, in so doing, drawing on some of the strengths of the private sector. But this also has risks. In our work at Birmingham since privatisation, we have seen how the negative experiences of staff during the competition constrained improvement, particularly during the early years of the new contract. G4S inherited a group of staff and managers who felt devalued, alienated, and 'tarred' by working for a 'failing' public sector institution. These staff were now responsible for delivering HMP Birmingham's promised improvement. A promising feature of Birmingham's development from this point onwards was the very able, ex-public sector Director who, having been asked to lead the prison through its transition stage, was persuaded to transfer to G4S as its new Director. This was a challenging decision for him, but his leadership proved to be a critical factor in what followed.

\section{Outcomes}

Our three year quality of life study at HMP Birmingham began shortly after the prison's transfer to G4S and concluded in December 2013 (Liebling et al., 2015). ${ }^{10}$ The team conducted detailed surveys of staff and prisoners' quality of life ( $k$ nown as $\mathrm{MQPL}^{11}$ and $\mathrm{SQL}^{12}$ ) alongside interviews and observation at all three stages. Three year mean data for all prisoner and staff quality of life dimensions can be found in tables 1 and 2 .

At time 1, December 2011, HMP Birmingham was performing poorly. The prison was characterised by long-serving and highly experienced staff who had been operating a well-oiled, but restricted regime.

\footnotetext{
10 The team consisted of Alison Liebling, Bethany Schmidt, Ben Crewe, Katherine Auty, Ruth Armstrong, Thomas Akoensi, Deborah Kant, Amy Ludlow and Alice levins. We are grateful to the team for their contributions to the project.

${ }^{11}$ Measuring the Quality of Prison Life; see Liebling, Crewe and Hulley, 2011.

${ }^{12}$ Measuring Staff Quality of Life; see Liebling, Price and Shefer, 2011.
} 
The senior management team (SMT) reflected this traditional character, consisting almost exclusively of older men, with operational backgrounds. Trust in the SMT was low, following the protracted bid process, but staff were willing to give the former public sector Director a chance and many expressed confidence in him. Staff-prisoner relationships were mixed, and were very poor on some wings. Overall prisoner quality of life was low (evaluated at 3.99 by prisoners overall on a ten point scale). The 'moral balance' at Birmingham was heavily weighted in favour of security rather than relationships (Liebling with Arnold, 2004). Many staff in the prison were keen to improve the prison's performance but the bid process had damaged professional confidence and feelings of investment in their work. Many staff expressed lack of clarity about the direction of travel or confidence that they had the right 'tools to do the job'. Staff had understood only one part of the message the procurement process was intended to communicate: that the way they had worked in the past was 'wrong'. As described above, there had not been any attempt to articulate or retain the public sector's core strengths, which include, at its best, the professional use of authority (see Crewe et al., 2014). The bid process had left a powerful legacy but, at time 1, it was uncertain whether an improved Birmingham would 'rise from the ashes'.

By time 2, December 2012, there were some significant improvements in prisoners' evaluations of their quality of life (albeit from a low level), over a relatively short period of time, particularly in levels of respect shown by staff towards prisoners. Most of the MQPL scores had moved in a positive direction. However, on the whole, these improvements to prisoner quality of life were not being led enthusiastically by staff. They were, rather, partly the result of perceived losses in staff power and some retreats from direct engagement with prisoners. Staff were emotionally fraught at the time of the second research visit, which coincided with a programme of voluntary redundancies. Drops in SQL scores reflected this. The eagerness of staff for change and their willingness to adopt a new agenda had waned, as they reported fatigue from multiple alterations to their working practices and numbers, with little support or clear leadership. Many staff retreated into offices, away from their work on wings, absorbed by their own 'private troubles'. The prison was disorderly and some powerful prisoners were exerting their authority on the wings. A drop in prisoners' rating of 'policing and security' reflected this. The prison had not combined the strengths of public and private sector prison staffing and management models, and nor had anyone leading the process articulated this possibility. Instead it was showing some of the weaknesses of each sector (negative staff attitudes towards prisoners and management and underuse of authority respectively). A change in the power balance between staff and prisoners, linked to lower resourcing, was evident (and has been replicated elsewhere). The reports written for Birmingham's senior management team were taken seriously, and concerted efforts were made to engage prisoners and the remaining (and therefore more committed) staff in the development of a safer and more constructive regime. Critically, at this point, staff in the public sector faced a reduction in their pay, numbers and conditions in a 'deal' that would avoid further wholesale privatisation but introduce much lower staffing levels in public sector prisons. Staff in Birmingham were awarded a pay rise above that negotiated by the public sector. The tables had turned.

By time 3, December 2013, there had been a turnaround. The prison was now showing signs of consistent improvement. Both prisoners and staff rated their quality of life and treatment significantly better than in 2011 and 2012 (time 3 overall quality of life scores were 4.75 and 5.93 respectively), and were feeling as though their prison 'was finally settling down'. Staff felt more secure in their jobs and described their work environment as more stable. Some staff had come to see the competition process more positively in light of the far-reaching restructuring taking place at public sector prisons from which Birmingham was shielded for at least 15 years by virtue of G4S' management contract with NOMS ('the grass is no longer greener on the other side'). Staff were starting to feel ably led and had started to grasp the bigger picture.

Staff views of senior management at time 3 were positive, though some complaints about insufficient recognition and support persisted. Feelings of safety, control and security among staff were positive, for 
the first time, although there were still concerns about the new flow of power among prisoners in a leanly staffed establishment and its under-policing by staff. Some staff continued to express concerns for safety linked to their reduced staffing numbers. 'Power-sharing' with prisoners was becoming the norm. There had been some symbolically significant and (in the research team's view) well-judged promotions of senior officers to junior managers. Highly talented and committed staff members were beginning to set a new tone in the prison and professional orientations of staff towards prisoners were improved. Prisoners noticed and appreciated these changes. 14 of the 21 MQPL dimensions received a more favourable rating in 2013 than in 2012, of which two were statistically significant: 'family contact' improved from 2.99 to 3.22 ( $p<0.05$ ) and 'care for the vulnerable' (prisoners at risk of suicide, self-harm or bullying from others) improved from 2.95 to 3.09 ( $p<0.1)$. The prison was (just) moving over the threshold from overall negative to overall positive ratings.

Overall, although several of the problems arising in the 2011 and 2012 studies reappeared, staff and prisoners were optimistic that Birmingham was on a positive trajectory. There was observational evidence to support perceptions of improvement. By comparison to the 2011 MQPL data, seven prisoner quality of life dimensions had improved significantly by 2013: 'respect/courtesy', 'humanity', 'decency', 'care for the vulnerable', 'staff-prisoner relationships', 'fairness' and 'personal autonomy'. Five of these are 'harmony' dimensions, suggesting that relationships - the interpersonal treatment of prisoners - had undergone the most significant improvement since transition in 2011. This suggested a real cultural shift. The staff who remained at Birmingham (who 'survived the transition') were by now committed to its future and those who had strongly resisted change had mostly moved on. The Director remained committed to the prison's future improvement, and staff were beginning to trust him and his team. Significantly, staff could see that since 2011, pay and conditions had become better in the private sector than in the public sector, as a result of stringent public sector savings programmes and dramatic reorganisations of prison work. Staff looked out at their public sector counterparts with some relief. We found turbulence, and less settled reconfigurations, in some public sector prisons in the period to follow (see, e.g. Justice Committee, 2015) - this is another story we hope to tell in the future. Stated briefly, better questions need to be asked about how cost, quality and legitimacy are traded off in the changing prison (Le Vay, 2016) and about why more use of cheaper imprisonment is preferred to less use of a better kind.

\section{Conclusions}

The questions raised in this article are sociological-penological and political. Changing legal, managerial, economic and political frameworks are impacting deeply and swiftly on prison life, culture and quality in England and Wales, with some risks to legitimacy, order and well-being, and some gaps in understanding. The new model of penal order is cheaper per prisoner place, but costly in relation to numbers imprisoned and risks faced. It takes very hard work and considerable skill to make the model work. One conceptual error has been in imagining a failing prison to be just that. To construct a process from an unstated but powerful set of assumptions about how the 'public sector has failed', and the 'private sector has the answers' omits to carry with it the significant strengths visible in public sector prison work (pride, loyalty, public service, experience and the competent use of authority). It underestimates some of the weaknesses inherent in private sector operations (cheap staff, high turnover, lack of loyalty, inexperience, and a drift into criminal justice work rather than a vocation). Some of these weaknesses are now being replicated in the public sector. The legal framework, and the ways in which the law was understood and mobilised, may have exacerbated a tendency to pay insufficient attention to the detail of workforce motivation, performance and culture. In addition, there is a lack of clarity about what the model of the aspired better prison is, what its underlying penological rationale might be, and what form of order any serious attempt at 'rehabilitation' rests upon. We followed the transition process with some alarm in the early days, and offered those who cared about Birmingham's future some constructive feedback based on our analysis when we could. We, like others, 
'hope the Prison Service has learned from the experience of staff at Birmingham, and that no other prison will be subject to such a lengthy process. We would also like to think that there is now much more consultation with staff, including an explanation of what privatisation [or competition] actually means.' (Bradbury, 2012, pp. 12-13). Transformative processes, whether involving wholesale or partial competition, bring about huge risks, complex human consequences, and some very difficult management challenges. Prisoners and staff are the unwitting subjects of penal experimentation. Better use of planning, penological honesty, and evidence-gathering on how far the new model achieves legitimate day-to-day experience, might avoid some of the more brutal consequences for staff and prisoners, might lead to a greater willingness to deploy much needed skill and determination to bring about the required improvement, and might expose greater awareness of the gap between rhetoric and reality. These transitions are a test case of whether and how the State can use its power legitimately.

\section{References}

Ascher, K. (1987). The Politics of Privatisation. London: Macmillan.

Baldwin, R. \& Kinsey R. (1985). Rules, Realism and the Police Act. Critical Social Policy, 12, 89-102.

Bradbury, B. (2012). How Birmingham went G4S. Independent Monitor Issue 105, August 2012.

Carter, P. (2003). Managing Offenders, Reducing Crime: a New Approach. London: TSO.

Carter, P. (2007). Securing the Future: Proposals for the Efficient and Sustainable Use of Custody in England and Wales. London: TSO.

Crewe, B., Liebling, A. \& Hulley, S. (2011). Staff culture, use of authority and prisoner quality of life in public and private sector prisons. Australian \& New Zealand Journal of Criminology, 44, 94-115.

Crewe, B., Liebling, A. \& Hulley, S. (2014). Heavy-light, absent-present: rethinking the "weight" of imprisonment. British Journal of Sociology, 65(3), 387-410.

Deakin, S. \& Sarkar, P. (2008). Assessing the long-run economic impact of labour law systems: a theoretical reappraisal and analysis of new time series data. Working Paper No. 367. Centre for Business Research, University of Cambridge.

DETR (1998). Modernising Local Government: Improving Local Services. London: TSO.

Dixon, D. (1997). Law in Policing: Legal Regulation and Police Practices. Oxford: Clarendon Press.

Garland, D. (2010). Penality and the Penal State. Criminology, 51(3), 475-517.

Harding, R. (2001). Private prisons. In M. Tonry (Ed.), Crime and Justice: A Review of Research 28 (pp. 265-346). Chicago and London: University of Chicago Press.

HAC (1987a). Third Report of the Home Affairs Committee: State and Use of Prisons, 1986-87, HC 35. London: House of Commons.

HAC (1987b). Fourth Report of the Home Affairs Committee: Contract Provision of Prisons, 1986-87, HC 291. London: House of Commons.

Hood, C. (1991). A public management for all seasons?. Public Administration, 69(1), 3-19 
Home Office (2004). Reducing Crime, Changing Lives. London: TSO.

HMCIP (2000). Report on a Full Announced Inspection of HM Prison Birmingham 10-18 July 2000 by HM Chief Inspector of Prisons. London: HMCIP.

HMCIP (2002). Report on a Full Unannounced Inspection of HM Prison Birmingham 21 - 25 October 2002. London: HMCIP.

HMCIP (2011). Report on an Unannounced Full Follow-Up Inspection of HMP Brixton 1-10 December 2010 by HM Chief Inspector of Prisons. London: HMCIP.

James, A. L., Bottomley, A. K., Liebling, A. \& Clare, E. (1997). Privatizing Prisons: Rhetoric and Reality. London: SAGE.

Justice Committee (2015). Ninth Report of Session 2014-15: Prisons: planning and policies, HC 309. London: House of Commons.

Le Vay, J. (2016) Competition for Prisons: Public or Private?. Bristol: Policy Press.

Liebling, A. (2011). Distinctions and distinctiveness in the work of prison officers: Legitimacy and authority revisited. European Journal of Criminology, 8(6), 484-499.

Liebling, A. with Arnold, H. (2004). Prisons and their Moral Performance: a Study of Values, Quality and Prison Life. Oxford: Clarendon Studies in Criminology, Oxford University Press.

Liebling, A., Crewe, B. \& Hulley, S. (2011). Conceptualising and Measuring the Quality of Prison Life. In D. Gadd, S. Karstedt \& S.F. Messner (Eds.), The Sage Handbook of Criminological Research Methods (pp. 358-372). London: Sage Publishing.

Liebling, A., Crewe, B., Hulley, S., Hutton, M., Clay, N. \& Kant, D. (2012). Understanding prisons: extended MQPL and SQL exercises: HMP Birmingham. Unpublished Prisons Research Centre report, Institute of Criminology, Cambridge: University of Cambridge.

Liebling, A. Hulley, S., Clay, N., Hutton, M., Kant, D. \& Ludlow, A. (2013). Birmingham prison: a benchmark study, one year on. Unpublished Prisons Research Centre report, Institute of Criminology, Cambridge: University of Cambridge.

Liebling, A., Price, D. \& Shefer, G. (2011). The Prison Officer. Cullompton, Devon: Willan Publishing.

Liebling. A., Schmidt, B., Crewe, B., Auty, K., Armstrong, R., Akoensi, T., Kant, D., Ludlow, A. \& levins, A. (2015). Birmingham prison: the transition from public to private sector and its impact on staff and prisoner quality of life - a three year study. NOMS Analytical Summary.

Liebling, A., Tait, S., Stiles, A., Durie, L. \& Harvey, J.; assisted by Rose, G. (2005). An Evaluation of the Safer Locals Programme. Report submitted to the Home Office, p. 215. Retrieved from http://www.crim.cam.ac.uk/people/academic research/alison liebling/SaferCustodyReport.pdf

Ludlow, A. (2012). Competition and contestability in action: restructuring the prison sector to achieve workforce and industrial change. Public Law, 3, 508-526. 
Ludlow, A. (2015). Privatising Public Prisons: Labour Law and the Public Procurement Process. Oxford: Bloomsbury.

Murphy, T. \& Whitty, N. (2016). Rights, Justice and Single-Mindedness. In S. Farrall, B. Goldson, I. Loader \& A. Dockley (Eds.) Justice and Penal Reform: Re-shaping the Penal Landscape (pp. 116-137). Oxon: Routledge.

Narey, M. (2001). Speech to the Prison Service Conference, Nottingham, Feb 2001.

NAO (2003). The Operational Performance of PFI Prisons: Report by the Comptroller and Auditor General. HC Session 2002-2003. London: TSO.

ODPM (2003). Local Government Act 1999: Part 1 - Best Value and Performance Improvement. ODPM circular 03/2003, 13 March 2003.

OGC (2006). Social Issues in Purchasing. London: OGC.

Power, M. (1997). The Audit Society: Rituals of Verification. Oxford: Oxford University Press.

Prison Reform Trust (2011). Bromley Briefings Prison Factfile. December 2011.

Sachdev, S. (2001). Contracting Culture: From CCT to PPPs: the Private Prison of Public Services and its Impact on Employment Relations. London: UNISON).

Schmidt, B.E. (2013). User Voice and the Prison Council Model: A Summary of Key Findings from an Ethnographic Exploration of Participatory Governance in Three English Prisons. Prison Service Journal, 209, 12-17.

Shefer, G. and Liebling, A. (2008). Prison privatisation: in search of a business-like atmosphere?. Criminology and Criminal Justice, 8(3), 261-278.

Table 1: Prisoner dimension mean comparisons - ANOVA test for linear trend 2011 to 2013 HMP Birmingham - Prisoners ${ }^{13}$

\begin{tabular}{|c|c|c|c|}
\hline & $N=111$ & $N=142$ & $N=164$ \\
\hline & 2011 & 2012 & 2013 \\
\hline \multicolumn{4}{|l|}{ Harmony Dimensions } \\
\hline Entry into Custody & 2.55 & 2.72 & 2.64 \\
\hline Respect/courtesy & 2.91 & 3.13 & $3.21 * *$ \\
\hline Staff-prisoner relationships & 2.91 & 3.07 & $3.11 \mathrm{f}$ \\
\hline Humanity & 2.76 & 2.90 & $2.97^{*}$ \\
\hline Decency & 2.54 & 2.63 & $2.73 *$ \\
\hline Care for the vulnerable & 2.90 & 2.95 & $3.09 *$ \\
\hline Help and assistance & 2.85 & 2.92 & 2.95 \\
\hline \multicolumn{4}{|l|}{ Professionalism Dimensions } \\
\hline Staff professionalism & 3.14 & 3.20 & 3.13 \\
\hline Bureaucratic legitimacy & 2.59 & 2.62 & 2.57 \\
\hline Fairness & 2.60 & 2.70 & $2.77 \mathrm{f}$ \\
\hline Organisation and consistency & 2.46 & 2.49 & 2.61 \\
\hline
\end{tabular}

${ }^{13} \mathrm{f}<0.1 ;^{*}<0.05 ;^{* *}<0.01 ;^{* * *}<0.001$; mean scores of 3.00 (the 'neutral' threshold) or over are shaded. 


\begin{tabular}{|l|c|c|c|}
\hline \multirow{2}{*}{ Policing and security } & 3.13 & 2.97 & 3.02 \\
\hline Prisoner safety & 3.16 & 3.23 & 3.23 \\
\hline Prisoner adaptation & 3.34 & 3.30 & 3.24 \\
\hline Drugs and exploitation & 2.71 & 2.74 & 2.66 \\
\hline Conditions and Family Contact Dimensions & 3.22 & \multicolumn{2}{|c|}{3.25} \\
\hline Conditions & 3.18 & 2.99 & 3.22 \\
\hline Family contact & 3.19 & & 2.77 \\
\hline Wellbeing and Development Dimensions & \multicolumn{2}{|c|}{} \\
\hline Personal development & 2.68 & 2.73 & $2.86 \mathrm{~J}$ \\
\hline Personal autonomy & 2.71 & 2.89 & 2.63 \\
\hline Wellbeing & 2.56 & 2.56 & 3.34 \\
\hline Distress & 3.41 & 3.36 & \\
\hline
\end{tabular}


Table 2: All staff dimension mean comparisons - 2011 compared to 2012, and 2012 compared to $2013^{14}$

HMP Birmingham - All staff ${ }^{15}$

\begin{tabular}{|c|c|c|c|c|}
\hline & $N=165$ & $N=126$ & $N=126$ & $N=131$ \\
\hline & 2011 & 2012 & 2012 & 2013 \\
\hline \multicolumn{5}{|l|}{ Management Dimensions } \\
\hline Attitudes towards the Director & 3.27 & $3.01^{*}$ & 3.01 & $3.55^{* * *}$ \\
\hline Treatment by senior management & 3.11 & 2.98 & 2.98 & $3.32 * *$ \\
\hline Treatment by line management & 3.13 & 3.07 & 3.07 & $3.60 * * *$ \\
\hline Relationship with the organisation & 3.12 & $2.51 * * *$ & 2.51 & $3.10 * * *$ \\
\hline Commitment & 3.64 & $3.13 * * *$ & 3.13 & $3.44 * *$ \\
\hline Recognition and personal efficacy & 2.75 & 2.70 & 2.70 & $3.11 * * *$ \\
\hline Involvement and motivation & 3.60 & $3.30 * *$ & 3.30 & $3.66 * * *$ \\
\hline Stress & 2.48 & $2.24 * *$ & 2.24 & $2.46^{*}$ \\
\hline Punishment and discipline & 2.84 & $2.58 * *$ & 2.58 & $2.80 *$ \\
\hline Dynamic authority & 3.38 & 3.27 & 3.27 & 3.24 \\
\hline \multicolumn{5}{|l|}{ Prisoner Orientation Dimensions } \\
\hline Professional support for prisoners & 3.68 & 3.57 & 3.57 & $3.74 *$ \\
\hline Positive attitudes to prisoners & 2.78 & 2.73 & 2.73 & 2.87 \\
\hline Trust, compassion and commitment towards prisoners & 3.76 & 3.69 & 3.69 & 3.73 \\
\hline Relationships with prisoners & 3.69 & 3.59 & 3.59 & $3.72 \mathrm{f}$ \\
\hline Overall Quality of Life score (1-10 mean) & 5.52 & $4.47 * * *$ & 4.47 & $5.93 * * *$ \\
\hline
\end{tabular}

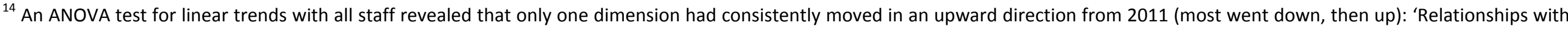
peers' increased from 3.67 in 2011 to $3.83(p<0.05)$ in 2013.

${ }^{15} \mathrm{f}<0.1 ; *<0.05 ; * *<0.01 ; * *<0.001$; mean scores of 3.00 (the 'neutral' threshold) or over are shaded.
} 